\title{
Adolescent adaptation before, during and in the aftermath of the Great Recession in the USA
}

\author{
Monica Kirkpatrick Johnson ${ }^{1}$, Jeremy Staff ${ }^{2}$, Megan E. Patrick ${ }^{3}$, and \\ John E. Schulenberg ${ }^{3}$ \\ ${ }^{1}$ Department of Sociology, Washington State University, Pullman, WA, USA \\ ${ }^{2}$ Department of Sociology, Pennsylvania State University, University Park, PA, USA \\ ${ }^{3}$ Institute for Social Research, University of Michigan, Ann Arbor, MI, USA
}

\begin{abstract}
$T$ his study examines the impact of the "Great Recession" (from December 2007 to June 2009) on 8th and 10th graders in the USA, using annual nationally representative data from the Monitoring the Future study. Historical changes in youth adjustment (self-esteem, depressed mood, risk taking, aggression and property crime), school achievement (grade point average [GPA], time spent on homework and educational expectations) and structured and unstructured activities (volunteering, employment, sports and evenings out for fun) were examined between 1991 and 2014. Overall, there were only slight changes in mean levels of adjustment, achievement and most youth activities. However, the percentage of youth working during the school year did decline during the Great Recession. Several longer-term trends were also evident, though not directly tied to the Great Recession. These include an increase in GPA, a decrease in time spent on homework, rising educational expectations and more time spent volunteering. Future work should assess how the shift to unpaid work activities (e.g. volunteering and internships) among youth is impacting the transition from school to work in the contemporary economy, and whether the Great Recession had deleterious impacts for younger children or among youth whose parents lost work or had their homes foreclosed.
\end{abstract}

Keywords: Adolescence; Historical trends; Recession; Population trends; Adjustment.

The USA experienced a "Great Recession" from December 2007 to June 2009 , marked by a nationwide decline in economic activity, broad increases in rates of joblessness, long-term unemployment and poverty, along with substantial reductions in income and wealth (Brundage, 2014; Grusky, Western, \& Wimer, 2011). Given the severity and length of this recession, as well as the slow pace of recovery, policymakers and researchers alike have been concerned about the effects of the recession on the American population and whether any such effects will be long-lasting. Whereas most of the attention has been on working-age adults and families more broadly, there are key reasons to pay attention to how adolescents specifically fared. Children and adolescents are developmentally more impressionable and vulnerable than adults; adverse effects of difficult economic times may cut deeper and leave lasting marks. In addition, adolescents are making decisions about school, work and romantic and sexual relationships that can set them on different pathways into adulthood.
In order to fully understand how the Great Recession may have affected adolescents, studies using a range of methodologies and samples are required. Studies with detailed data on the extent to which adolescents experience economic shocks in their families, and those following the development of individuals over time, are complemented by those of the type we employ here-an examination of broad, population-level trends. We pursue two research questions. First, we ask how adolescents in the USA as a whole were doing during and after the Great Recession compared to beforehand. Second, we ask whether any changes experienced by the adolescent population were concentrated among minorities and those in lower socio-economic status families, groups who are more economically vulnerable in the USA. To address these questions, we examine repeated cross-sectional data for 8th and 10th grade students from the ongoing, nationally representative Monitoring the Future (MTF) study. We examine a broad range of indicators for how adolescents have fared, sketching out the "big picture." These

Correspondence should be addressed to Monica Kirkpatrick Johnson, Department of sociology, Washington State University, Pullman, WA 99164-4020, USA. (E-mail: monicakj@wsu.edu). 
indicators tap adjustment (self-esteem, depressed mood, risk taking, aggression and property crime), achievement (grade point average [GPA], time spent on homework and educational expectations) and activities (volunteering, employment, sports and evenings out for fun). We examine trends in these measures assessed annually with new national samples of 8th and 10th graders over more than two decades (1991-2014), allowing observation both before, during and after the Great Recession, as well as for two previous recessions (1991 and 2001).

\section{THEORETICAL BACKGROUND}

Contemporary approaches to understanding adolescence as a life stage and the developing young person him or herself emphasise the importance of historical period and social context (Crosnoe \& Johnson, 2011). Adolescents are embedded in families, institutions and the larger society, and these environments shape development along multiple dimensions. This basic observation orients us as we consider what kinds of impacts a severe recession can be expected to have on adolescents. It suggests we look to the wider societal environment in which adolescents are learning, planning, taking risks and making investments. It also directs our attention to key institutions such as the labour market, as it expands, contracts and alters the reward structure for varying skills, and to families, as the most immediate social environment or "microsystem" through which social change is mediated (Bronfenbrenner, 1979; Elder, 1999). With this orienting framework, we observe both direct ways in which a major recession can affect adolescents, as well as indirect ways through the family's experience of economic change.

Most directly, major negative changes in economic conditions affect adolescents' labour market opportunities as companies lay off existing employees and offer fewer openings for new labour market entrants (Staff, Johnson, Patrick, \& Schulenberg, 2014). The Great Recession may have also affected the way adolescents think about the future, with implications for well-being and behavioural choices. Certainly the long-term economic restructuring in the USA, encompassing the rising premium to a 4-year college degree, has made pursuit of higher education more desirable (Goyette, 2008). Nearly $40 \%$ of ninth graders in the recent High School Longitudinal Study expect to achieve beyond the bachelor's degree, anticipating earning a Master's degree or higher (National Center for Education Statistics, 2015). With bachelor's degree holders relatively protected in the Great Recession (e.g. unemployment at half the rate of high school graduates in 2009; Grusky et al., 2011), as well as in the years immediately following the recession (Vuolo, Mortimer, \& Staff, 2016), obtaining a 4-year college degree may have become even more important to adolescents. With educational expectations already so high, not much change may be evident in them (i.e. there may be ceiling effects), but perhaps adolescents' investments in studying rose along with other activities designed to assist in presenting competitive applications to college (e.g. volunteer work). If adolescents perceive higher stakes in education and the labour market, increased efforts aimed at succeeding in these realms may reduce time spent in leisure pursuits.

In contrast to these arguments, there are countervailing trends that complicate such predictions. Despite the growing value of education in the labour market, the cost of higher education rose as well, particularly during the Great Recession (The College Board, 2015). Although many young people and their families were able to find ways to meet these costs, others were likely priced out. Studies have shown that risky behaviour among adolescents rises when higher education becomes less affordable (Cowan, 2011). For those who may have been on the margin with respect to future educational routes, there may have been even less to lose by engaging in risky behaviour.

Adolescents may also have been impacted indirectly, particularly through their families' experiences of the Great Recession. Specifically, adolescents' well-being may have declined as their parents lost jobs or felt greater employment insecurity, had their homes foreclosed, or witnessed their savings dry up. More than one in three households in the USA experienced unemployment, negative equity in their home, or missed a house payment between 2008 and 2009 (Hurd \& Rohwedder, 2010). Burgard (2012) also reports an uptick in the rate of serious psychological distress among adults in the USA during the recession.

Specific, disruptive events such as parental job loss and residential moves increase during recessions, and have generally negative impacts on child and adolescent development, particularly among those in lower socio-economic status families (Kalil, 2013). Financial stress on parents can find its way to children through parents' own deteriorated well-being and increased conflict between parents (Conger, Ge, Elder, Lorenz, \& Simons, 1994). As such, adolescents may have experienced more stress at home, as well as less support from parents in coping with even routine difficulties.

Despite strong arguments suggesting major impacts, it is equally important to consider that the Great Recession may have had limited or weak effects on adolescents. One possibility is that adolescents already faced uncertain futures prior to the Great Recession, and any adaptive responses have been ongoing in the face of longer-term economic trends. In addition, while some families experienced major issues, many parents may have been able to buffer the impact on their adolescent children by drawing on their financial as well as emotional reserves to weather the tough times. Studies of adults support the idea that there were not wholesale effects of the Great Recession across all aspects of life and well-being. Although there 
is evidence of decline in mental health, other aspects of health showed little change, at least in the short-run (Burgard, 2012). ${ }^{1}$ And scholars tracking public opinion have noted the "surprisingly weak effect" recessions have had on Americans' views on economic and social issues (Kenworthy \& Ownes, 2011).

We have limited empirical evidence to date with which to evaluate the effects of the Great Recession on adolescents. Two recent studies drawing on data from a long-term panel study in the USA tracked achievement orientations and work values of adolescents with changes in parents' incomes and employment conditions. Findings from the first study (Mortimer, Zhang, Hussemann, \& $\mathrm{Wu}, 2014)$ indicated that adolescents' expectations of economic success in adulthood declined with increases in parents' financial problems over a 2-year period, but only among those whose parents had no more than a high school diploma; educational aspirations were also lowered in the face of declining parental income if parents had experienced intermittent unemployment in the decade prior. The second study (Johnson \& Mortimer, 2015) found differences in adolescents' work values, or the importance they attach to different job features. Adolescents whose parents experienced increases in income held stronger extrinsic work values (i.e. greater emphasis on income, security, a job that people regard highly, and advancement opportunities). Those whose parents experienced a decline in job security held weaker extrinsic values. Findings for intrinsic values were very similar, with increased income positively related to children's intrinsic work values (greater emphasis on decision-making authority, responsibility, opportunities to use one's skills and abilities, learning opportunities, contacts with people and opportunities to help others), and a decline in parental job security negatively related to intrinsic work values. Representing a more disruptive change in the family, parental unemployment was associated with higher extrinsic and intrinsic orientations among children when parents had low levels of education (high school degrees or less). The findings of this study support a generalisation model, wherein work values are stronger when jobs are more rewarding (and weaker when they become less so).

Taken together, these two studies suggest that changing parental circumstances in the Great Recession may shape adolescents' achievement-related orientations, though often differentially by how families are positioned economically. Looking outside the USA, having parents out of work was associated with Not in Education, Employment or Training (NEET) status and duration in the Great Recession in England, particularly among those teenagers with weaker educational achievement orientation (Schoon, 2014).

In sum, research on adolescent adjustment and attainment in the Great Recession is limited. We know that many adults' financial circumstances changed greatly during and in the aftermath of the recession, but consideration of other aspects of adults' orientations and well-being suggest variable and sometimes short-term effects. In this study, we draw on national data collected annually from large samples of US adolescents in the 8th and 10th grades, tracking aggregate trends in a wide range of indicators in order to build a more complete picture of the Great Recession's impact on youth. Our first research question asks whether aggregate trends in adolescent adjustment, achievement and participation in activities changed during or after the Great Recession. Because, as we note above, there are competing possibilities for how adolescents may have been affected, we do not hypothesise that historical change occurred in specific directions. Our second question asks whether any changes tied to the Great Recession were disproportionately evident in groups more vulnerably positioned in the economy. Our review of past studies suggests that economic changes have stronger effects on disadvantaged groups. Thus we examine whether historical trends in adolescent adjustment, achievement and participation in activities differed between Whites and non-Whites and by mothers' education level, two key indicators of disadvantage.

\section{METHOD}

\section{Data}

Based on a repeated cross-sectional design, the MTF study continues to collect data on nationally representative samples of middle and high school students each year. ${ }^{2}$ Since 1991, in-school surveys have been collected from approximately 32,500 8th and 10th grade students each year. Students were randomly selected from approximately 160 public and private schools, and youth completed questionnaires with multiple choice items in the classroom. About $90 \%$ of students responded to these surveys, with nearly all non-response due to absenteeism. Although school-based survey administrations exclude dropouts, estimates indicate a dropout rate of less than $2 \%$ for eighth graders (age 13-14) and less than 7\% for 10th graders (age 15-16) in recent years (Miech, Johnston, O'Malley, Bachman, \& Schulenberg, 2016). We used weights in all of our analyses to correct for the multistage sampling procedure. The MTF uses multiple survey

\footnotetext{
${ }^{1}$ Burgard (2012) does note a rise in reports of foregoing dental care, prescription medicine and eyeglasses in 2009, raising the possibility that health effects may arise later.

${ }^{2}$ Details of the Monitoring the Future study are available at http://monitoringthefuture.org/. Data from these grade cohorts are available to download at the Inter-university Consortium for Political and Social Research (http://www.icpsr.umich.edu/icpsrweb/ICPSR/series/35).
} 
forms (distributed randomly) to increase survey breadth and limit respondent burden, so not all of the survey items used in these analyses were asked of all youth. Thus, our analysis sample ranged from 245,682 to 773,862 students depending on the outcome.

In this article, we use 24 cohorts of 8th and 10th graders (from 1991 to 2014) to assess historical trends before, during and after the Great Recession. In the sample, approximately 53\% are girls; $61 \%$ are White, $13 \%$ are Black, $13 \%$ are Hispanic, $4 \%$ are Asian and 9\% are another race/ethnicity; approximately $42 \%$ of the students reported that their mother had completed college.

\section{Measures of adolescent adjustment, achievement and activities}

We consider five indicators of youth adjustment that have been used in previous MTF analyses (e.g. Keyes et al., 2015; Maslowsky, Schulenberg, \& Zucker, 2014). Self-esteem is a summary scale of the mean of eight items $(\alpha=.88)$, such as "I take a positive attitude toward myself," "I feel I am a person of worth, on an equal plane with others" and "I am able to do things as well as most people." Responses on each item ranged on a 5-point scale from "disagree" to "agree." Symptoms of depressive affect is an average of four items with the same scale $(\alpha=.76)$, such as "Life often seems meaningless" and "The future often seems hopeless." Risk taking includes two items $(\alpha=.78)$ : "I get a real kick out of doing things that are little dangerous" and "I like to test myself every now and then by doing something a little risky," with responses ranging on a 5-point scale from "disagree" to "agree." Interpersonal aggression is a mean scale of three items $(\alpha=.80)$ indicating how often in the past year the respondent had: "taken part in a fight where a group of your friends were against another group," "hurt someone badly enough to need bandages or a doctor" or "gotten into a serious fight in school or at work." Finally, property crime is a mean scale based on five items $(\alpha=.78)$, such as how often in the past year respondents had taken something not belonging to them worth under $\$ 50$, sold an illegal drug, or damaged school property on purpose. For both the aggression and property crime items, responses ranged from 1 "not at all" to 5 "5 or more times."

We included three single-item measures of academic achievement. Youth self-reported their GPA during the current school year (ranging from $1=$ "D or below" to $9=$ "A"). Educational expectations assessed how likely the adolescent felt that they were to graduate from a 4-year college program (ranging from $1=$ "definitely won' $t$ " to $4=$ "definitely will"). Youth were also asked to report about how many hours they spend on their homework in an average week (ranging from $1=$ " 0 hours" to $7=$ " 25 or more hours" per week).

Finally, we examined involvement in paid work, evenings out for fun, civic engagement and exercise or sports participation. Specifically, we created a binary measure indicating whether the adolescent was currently or had worked in a paid job during the school year $(1=$ yes, $0=$ no). We included a binary measure assessing whether the young person volunteers or participates in community service at least monthly $(1=$ yes, $0=$ no). We also created a binary measure of whether they played sports or exercised almost every day $(1=$ yes, $0=$ no). Finally, youth were asked: "During a typical week, on how many evenings do you go out for fun and recreation? (Don't count things you do with your parents or other adult relatives)." We created a binary measure distinguishing respondents who go out for fun and recreation at least one evening per week (1) versus those who do not $(0)$.

\section{RESULTS}

In this descriptive study we present trend lines across years 1991-2014 in a series of figures, and ordinary least squares (OLS) and logistic regression models in which we estimate the size and statistical significance of historical change on each outcome (see Table 1). Regression models specify 2008, the height of the recession, as the reference category for the comparison across years and provide the coefficients when statistically significant. Given the very large sample sizes involved, it is important to keep in mind that some statistically significant differences can still be very small in magnitude.

Figure 1 shows averages of self-esteem, depressed mood, risk-taking, interpersonal aggression and property crime from 1991 to 2014. Although each is on a 5-point scale, historical trends within indicators are the focus (vs. comparison across indicators), as the meaning of the five points differs across them. On average, throughout the observation period, youth "mostly agreed" with the survey items indicating positive self-esteem, and "mostly disagreed" with the items referencing depressed mood. Respondents neither disagreed nor agreed on average with the risk-taking items. The indicators of interpersonal aggression and property crime averaged between "not at all" and "once in the past year" from 1991 to 2014. Results show little change in mean levels of self-esteem, depressed mood, risk-taking, interpersonal aggression or property crime during the Great Recession (i.e. 2007 to 2009), or during prior recessions (i.e. 1991 or 2001). Overall, the trends show remarkable stability over the 24 years of assessment, though there appears to be a recent trend of decreasing self-esteem and increasing depressive affect. Estimates in the first two columns of Table 1 indicate that self-esteem was lower and depressive affect higher in recent years than in 2008, although the difference is quite small (effect size for self-esteem in 2014, the largest difference, is less than one-fifth of a standard deviation). 


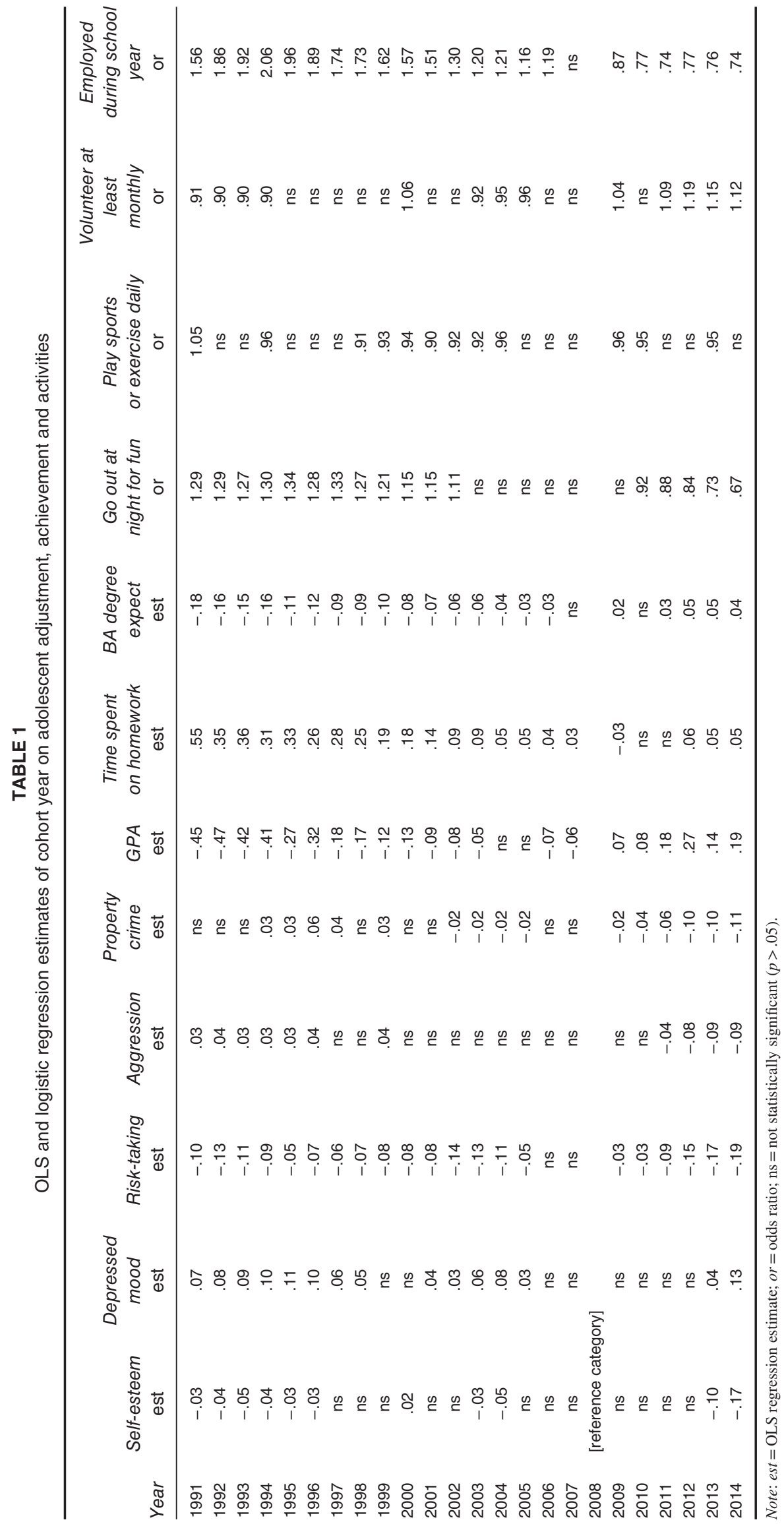




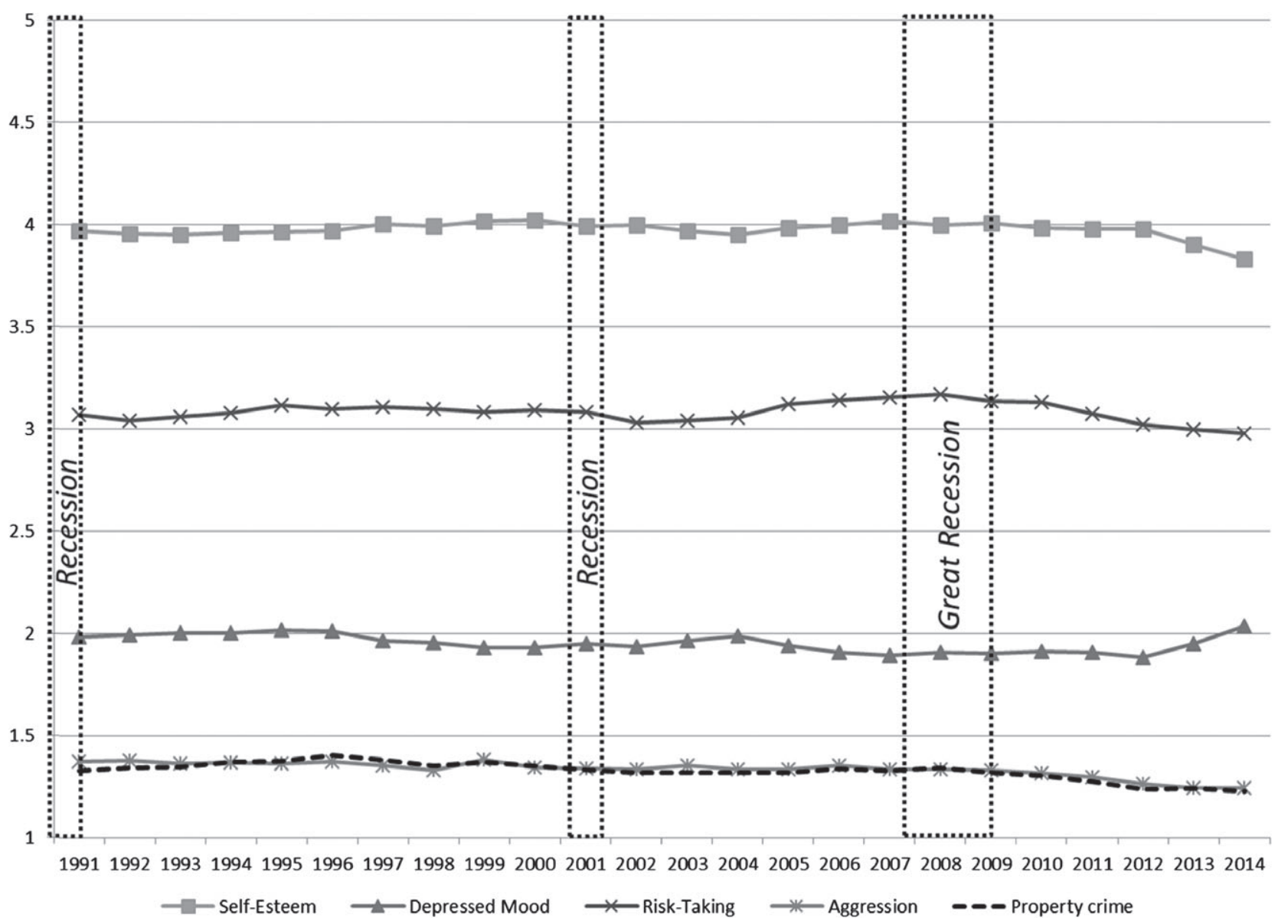

Figure 1. Adolescent adjustment from 1991 to 2014 (MTF 8th and 10th graders, $n=247,101$ to 578, 187).

Figure 2 displays mean levels of school achievement from 1991 to 2014. The scales differ in important ways across these indicators, so again trends within indicators is the focus. GPA and educational expectations show a slight increase, and time spent on homework a slight decrease, during the Great Recession. However, a closer examination of Figure 2 reveals a more gradual change in achievement indicators over the past 24 years. For instance, GPA rose steadily from students averaging between a "B-" and a "B" in 1991 to averaging over a "B" in 2014. Educational expectations also rose slightly from 1991 to 2014, as the average teenager nowadays expects he or she "definitely will" graduate with a 4-year college degree. Time spent on homework also steadily declined over the past 24 years so youth now average under 5 hours of homework per week.

Figure 3 shows the percentage of adolescents from 1991 to 2014 who volunteered at least monthly, who were employed during the school year, who played sports or exercised at least daily, or who went out for fun and recreation at least one night per week. Volunteering, sports participation and going out for fun changed little during the Great Recession. Youth employment showed a sharp decline during the recession that has slowed in recent years. This decline is embedded in a longer-term trend of reduced participation in paid work. A higher percentage of youth nowadays volunteer monthly than hold a job during the school year. Youth are also less likely to go out at least one night per week for fun, dropping from $80 \%$ of youth in the early 1990s to $68 \%$ in 2014 .

With respect to our second research question, ${ }^{3}$ we found little evidence of moderation by race/ethnicity (Blacks, Hispanics and Whites), and mother's education (high school graduation or less vs. some college or more, which is a proxy for socio-economic status) for the five indicators of adjustment, the three indicators of achievement and the four indicators of activities. Patterns of difference on these indicators by race/ethnicity

\footnotetext{
${ }^{3}$ These results are not shown but are available upon request. Models were estimated separately across subgroups and then z-tests were used to compare the equality of the time estimates. Although not our primary focus, it is notable that supplemental analyses also revealed little moderation by age (8th and 10th grade) or gender as well.
} 


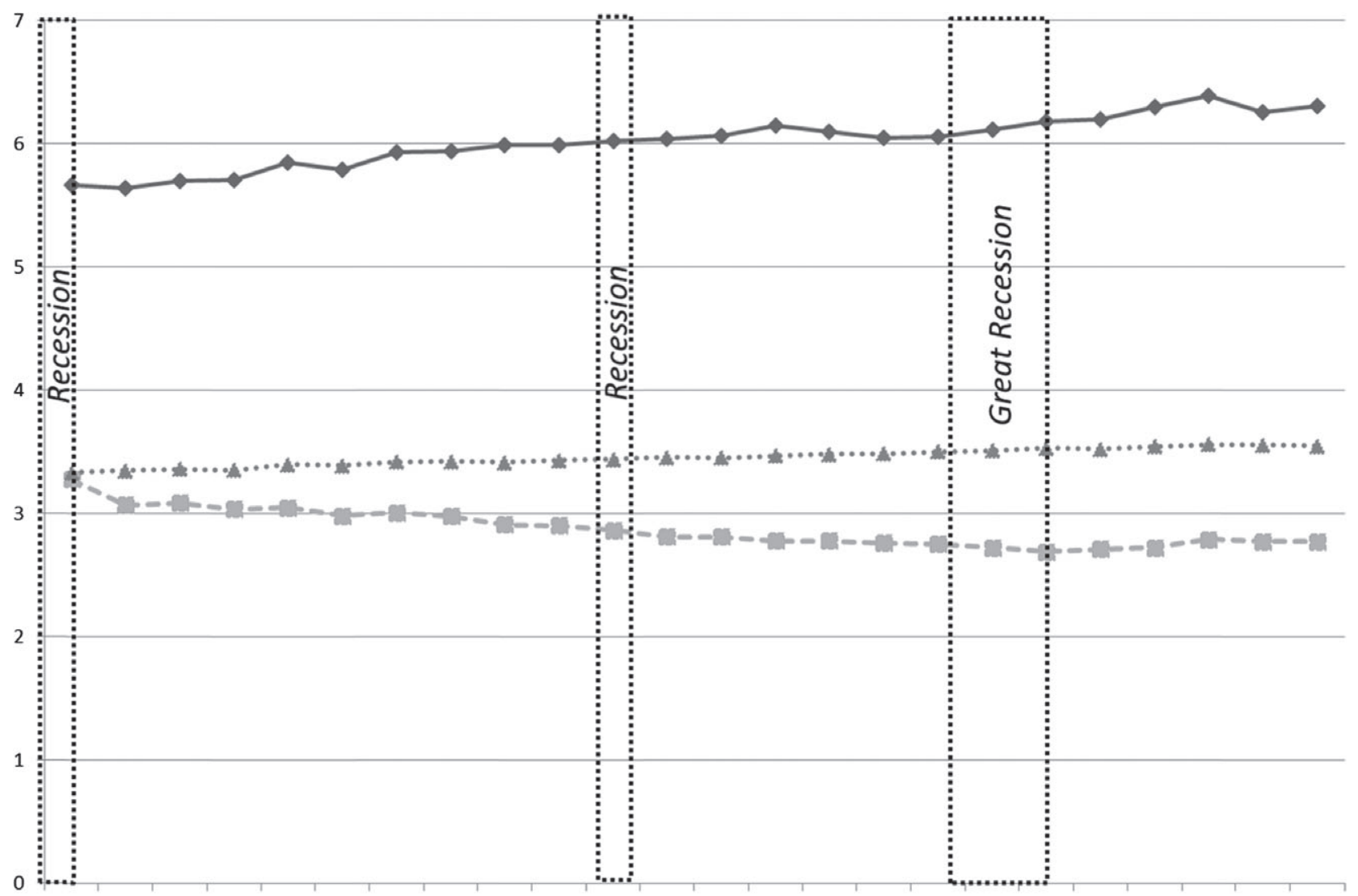

199119921993199419951996199719981999200020012002200320042005200620072008200920102011201220132014

$\longrightarrow$ GPA -1 - Time spent on homework $\quad \cdots \cdots$ BA degree expectations

Figure 2. Adolescent achievement from 1991 to 2014 (MTF 8th and 10th graders, $n=752,878$ to 759, 360).

and maternal education were thus maintained over time.

\section{DISCUSSION}

The purpose of this study was to describe possible changes in adolescent functioning and adjustment over the past quarter century, giving attention to any changes in years of economic downturn. We used large national samples of US teenagers to examine yearly changes in multiple indicators of youth adjustment, achievement and activities from 1991 to 2014, with a particular emphasis on shifts that coincided with the global Great Recession across years 2007-2009. Overall, we observed only slight changes in the years surrounding the Great Recession in mean levels of five indicators of adjustment (self-esteem, depressed mood, risk-taking, interpersonal aggression and property crime), three indicators of achievement (GPA, educational expectations and time spent on homework) and three variables referencing youth activities (volunteering, playing sports or exercising and going out with friends). Similarly, these indicators did not appreciably change during or in the aftermath of other economic recessions, such as in 1991 or 2001. Not surprisingly, the percentage of youth working during the school year did decline during the Great Recession, and school-year employment is particularly low among youth today (also shown by Staff et al., 2014), with some evidence to suggest similar declines in previous years of economic downturn, especially in the aftermath of the 2001 recession. Thus, our findings indicate that youth have been affected by the recent and previous economic downturns in a very limited but direct way - through their own labour market opportunities. With respect to these employment trends, as well as all other measures we examined, we found no evidence that historical shifts were any more apparent among disadvantaged groups.

Though many aspects of the social development of teenagers appear not to be directly affected by the Great Recession or previous economic downturns, our results show some broad changes among youth across the past quarter century. For instance, compared to youth in the 1990s, teenagers nowadays report higher overall GPAs while spending less time overall completing homework. As other research has reported using data from the MTF, educational expectations have risen, with the majority of 


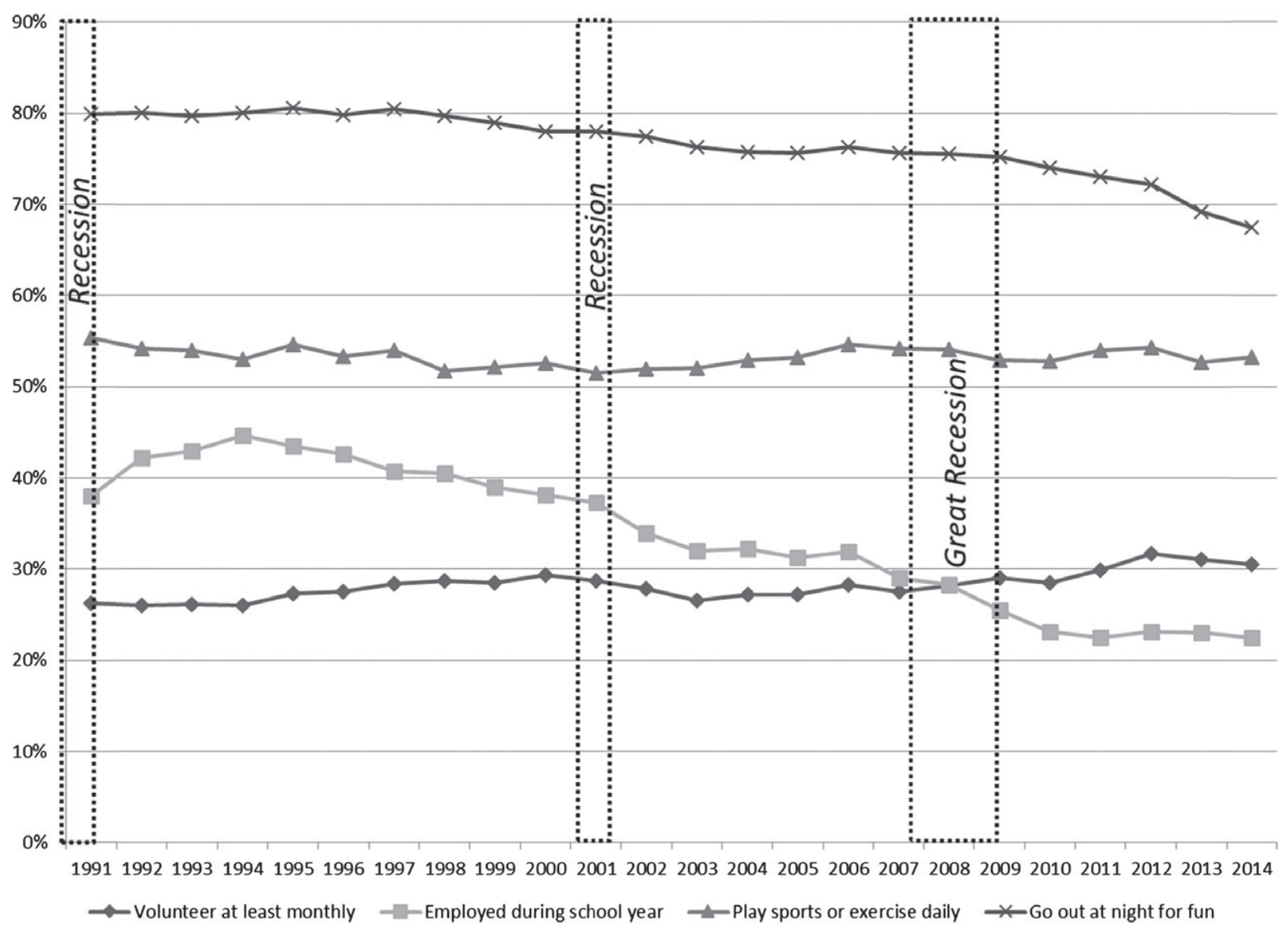

Figure 3. Adolescent activities from 1991 to 2014 (MTF 8th and 10th graders, $n=739,218$ to 773, 862).

contemporary youth expecting to "definitely" graduate with at least a Bachelor's degree. In addition, the steep drop in teenage employment in the post Great Recession period has coincided with a more gradual increase in the percentage of teens who are spending time as volunteers or engaged in community activities (Syvertsen, Wray-Lake, Flanagan, Osgood, \& Briddell, 2011). Finally, it is clear that recent cohorts of youth are spending less time hanging out with friends in unstructured activities that are away from parents, teachers or other adult guardians. Though it is unlikely that the Great Recession is directly involved in these recent trends, it is no doubt part of the myriad economic, social and technological changes that contribute to the changing macrosystem of today's youth undergirding these social and well-being shifts. The repeated cross-sectional design of the MTF study allowed us to take a wide view of these trends before, during and in the years following the Great Recession.

We do observe that the last several cohorts have experienced slightly higher symptoms of depressive affect and lower self-esteem, and unlike the changes noted above, these were not embedded within longer-term trends. These changes could reflect a delayed effect of the recession, emerging about $4-5$ years afterwards, perhaps as it became clearer that opportunities in the economy were not going to revert back to pre-recession levels. It is also possible that changes to well-being were limited to children whose families suffered major economic losses, and with more individual families affected as the poor economy dragged on (even past the official end of the Great Recession), it may have taken several years for this trend to become visible at the population level. Though we do not address these or alternative, non-recession, explanations any further here, we encourage continued monitoring. The differences observed were quite small, but if they continue they could become consequential.

In previous research using MTF data (Staff et al., 2014), we documented the decline of employment among US teenagers, who once commonly held part-time jobs after school or on weekends during the school year. Though adults have experienced some recovery in terms of unemployment and overall rates of labour force participation since the Great Recession (though still not up to pre-recession levels; see Brundage, 2014), no recovery is evident in rates of paid work among 8th and 10th graders since the Great Recession, nor for previous recessions in 1991 and 2001. In fact, the trends indicate 
precipitous drops in youth employment during recession years that never recovered. Change in the rates of employment among teenagers has the potential to reduce youth's opportunities to build human capital and learn important life skills, but also lessens exposure to the risks associated with intensive paid work in adolescence, such as compromising school performance or increasing problem behaviours (see Staff, Mont'Alvao, \& Mortimer, 2015, for a review). Our results indicated that youth increasingly appear to be substituting unpaid work activities (i.e. volunteering) to some extent for part-time jobs during the school year, as a higher percentage of teenagers in 2014 volunteered in the past month then held a job during their current school year. As suggested by the recent Institute of Medicine (2014) consensus study on health and safety during the transition to adulthood, future work should assess how the shift to unpaid work activities (e.g. volunteering and internships) among youth is impacting the transition from school to work in the contemporary economy.

Though our results suggest that teenagers are largely shielded from economic recessions, including the Great Recession, it is important to note that these population trends may mask adjustment problems for youth whose families or communities were severely hit by the Great Recession. The MTF study does not collect data on parental job loss, unemployment or recent family economic setbacks, such as a home foreclosure, bankruptcy or significant loss of savings. Adolescent well-being may be expected to drop when parents' own well-being does, or when conflict in the family increases, but we do not have information about parental well-being or family conflict. Likewise, our repeated cross-sectional data may also mask changes at the individual level that panel data following development of adolescents over time could reveal. An additional limitation to our study is that while we examined a broad range of indicators of social and behavioural development, all measures were self-reported and some were based on only single questionnaire items.

An interesting question is whether younger children might be more vulnerable to economic recessions than the cohorts of 8th and 10th graders we observed in this study. Elder's (1999) classic study of youth coming of age during the Great Depression revealed how family economic hardship had an especially strong effect on young children. Older children, by contrast, were better able to weather the stressors and struggles associated with the Great Depression by working to help with family expenses. In the analyses we show here, the most recent eighth graders were elementary age during the Great Recession. Population level changes for elementary age children during that time would therefore be evident in the most recent eighth graders in our sample, so if population trends existed for children that age, they have dissipated since then. Older teenagers and young adults may also be more vulnerable to economic downturns compared to the 8th and 10th graders we highlight here, as they may find it difficult to establish adult independence (e.g. obtain career-relevant work, leave the parental home) in troubled economic times. Furthermore, when work opportunities are in short supply, older youth may expect less from their future jobs, and these weakened work values in turn could negatively impact later career opportunities and socio-economic attainment (Johnson, Sage, \& Mortimer, 2012).

In conclusion, results did not indicate strong direct detrimental effects for US 8th and 10th grade youth during the Great Recession, although the percentage of youth working during the school year did decline. More general historical changes, not directly linked to the Great Recession, such as an increase in GPA, decrease in time spent on homework, higher educational expectations and more time spent volunteering, were found across the past quarter century; more recently there has been a decline in unstructured time with friends and very recently there has been a decline in self-esteem and an increase in symptoms of depressive affect. Additional research regarding how these changes are affecting youth, including how the shift from paid to unpaid work activities (e.g. volunteering and internships) affects the transition to adulthood, is needed. Moreover, while our study casts doubt on any wholesale negative impact of the Great Recession, studies using alternative methods and targeting other age groups are needed. In particular, a closer look examining the impacts of the Great Recession for youth who were most directly affected by economic hardship (e.g. those whose parents lost their jobs or who were displaced from their homes) would be highly valuable.

Manuscript received April 2016 Revised manuscript accepted August 2016 First published online October 2016

\section{REFERENCES}

Bronfenbrenner, U. (1979). The ecology of human development: Experiments by nature and design. Cambridge, MA: Harvard University Press.

Brundage, V. (2014). Trends in unemployment and other labor market difficulties. In Beyond the numbers: Employment \& unemployment, 3, 25. Washington, DC: U.S. Bureau of Labor Statistics.

Burgard, S. (2012). Health, mental health, and the great recession. Stanford, CA: Stanford Center on Poverty and Inequality.

College Board (2015). Trends in college pricing 2015. The College Board.

Conger, R. D., Ge, X., Elder, G. H., Lorenz, F. O., \& Simons, R. (1994). Economic stress, coercive family process, and developmental problems of adolescents. Child Development, 65, 541-561.

Cowan, B. (2011). Forward thinking teens: The effects of college costs on adolescent risky behavior. Economics of Education Review, 30, 813-825. 
Crosnoe, R., \& Johnson, M. K. (2011). Research on adolescence in the $21^{\text {st }}$ century. Annual Review of Sociology, 37, 439-460.

Elder, G. H., Jr. (1999). Children of the great depression: Social change in life experience $\left(25^{\text {th }}\right.$ anniversary ed.). Boulder, CO: Westview Press.

Goyette, K. A. (2008). College for some to college for all: Social background, occupational expectations, and educational expectations over time. Social Science Research, 37, 461-484.

Grusky, D. B., Western, B., \& Wimer, C. (Eds.) (2011). The great recession. New York, NY: Russell Sage Foundation.

Hurd, M. D., \& Rohwedder, S. (2010). Effects of the financial crisis and great recession on American households. Washington, DC: The National Bureau of Economic Research.. Retrieved from http://www.nber.org/papers/w16407

Institute of Medicine (2014). Investing in the health and well-being of young adults. Washington, DC: The National Academies Press.. Retrieved from http://iom.edu/Reports/ 2014/Investing-in-the-Health-and-Well-Being-of-YoungAdults.aspx

Johnson, M. K., \& Mortimer, J. T. (2015). Parents' work and financial conditions in the great recession and adolescents' work values. Journal of Vocational Behavior, 87, 89-100.

Johnson, M. K., Sage, R. A., \& Mortimer, J. T. (2012). Work values, early career difficulties, and the U.S. economic recession. Social Psychology Quarterly, 75, $242-267$.

Kalil, A. (2013). Effects of the Great Recession on child development. Annals of the American Academy of Political and Social Science, 650, 232-249.

Kenworthy, L., \& Ownes, L. A. (2011). The surprisingly weak effect of recessions on public opinion. In D. G. Grusky, B. Wester, \& C. Wimer (Eds.), The Great Recession (pp. 196-219). Russell Sage Foundation.

Keyes, K. M., Jager, J., Hamilton, A., O’Malley, P. M., Miech, R. A., \& Schulenberg, J. E. (2015). National multi-cohort time trends in adolescent risk preference and the relation with substance use and problem behavior from 1976 to 2011. Drug and Alcohol Dependence, 155, 267-274.
Maslowsky, J., Schulenberg, J. E., \& Zucker, R. (2014). Influence of conduct problems and depressive symptomatology on adolescent substance use: Developmentally proximal versus distal effects. Developmental Psychology, 50(4), 1179-1189.

Miech, R. A., Johnston, L. D., O’Malley, P. M., Bachman, J. G., \& Schulenberg, J. E. (2016). Monitoring the future national survey results on drug use, 1975-2015: Volume I, Secondary school students. Ann Arbor, MI: Institute for Social Research, The University of Michigan.. Retrieved from http://monitoringthefuture.org/pubs.html\#monographs

Mortimer, J. T., Zhang, L., Hussemann, J., \& Wu, C. (2014). Parental economic hardship and children's achievement orientations. Longitudinal and Life Course Studies, 5(2), $105-128$.

National Center for Education Statistics. (2015). High school dropouts and stopouts: Demographic backgrounds, academic experiences, engagement, and school characteristics. U.S. Department of Education, NCES 2015-064.

Schoon, I. (2014). Parental worklessness and the experience of NEET among their offspring: Evidence from the Longitudinal Study of Young People in England (LSYPE). Longitudinal and Life Course Studies, 5, 129-150.

Staff, J., Johnson, M. K., Patrick, M., \& Schulenberg, J. E. (2014). The Great Recession and recent employment trends among secondary students in the United States. Longitudinal and Life Course Studies, 5, 173-188.

Staff, J., Mont'Alvao, A., \& Mortimer, J. T. (2015). Children at work. In M. H. Bornstein, T. Leventhal, \& R. Lerner (Eds.), Handbook of child psychology and developmental science. Ecological settings and processes (Vol. 3, 7th ed.). New York, NY: Wiley.

Syvertsen, A. K., Wray-Lake, L., Flanagan, C. A., Osgood, D. W., \& Briddell, L. (2011). Thirty-year trends in U.S. adolescents' civic engagement: A story of changing participation and educational differences. Journal of Research on Adolescence, 21, 586-594.

Vuolo, M., Mortimer, J. T., \& Staff, J. (2016). The value of educational degrees in turbulent economic times: Evidence from the youth development study. Social Science Research, $57,233-252$. 